\title{
LOS CUERPOS QUE NOS MIRAN DESDE LEJOS. FIGURAS DEL OTRO Y TÉCNICA DEL OBSERVADOR EN LA HERIDA EN LA LENGUA, DE CHANTAL MAILLARD
}

\author{
BODIES THAT LOOK AT US FROM AWAY. \\ FIGURES OF OTHERNESS AND THE OBSERVER'S TECHNIQUE \\ IN CHANTAL MAILLARD'S LA HERIDA EN LA LENGUA
}

\section{Manuel A. BROULLÓN-LOZANO \\ Universidad Complutense de Madrid mabroullon@ucm.es}

\begin{abstract}
Resumen: La creación poética de Chantal Maillard se construye en variación sobre los mismos temas y figuras: hilos, agujeros, cuerpos, heridas, tiempo, miradas, dificultad de decir. Bajo estos temas y figuras, el problema de la otredad: ¿cómo representar?, ¿cómo entrar siquiera en contacto auténtico con lo otro? En este artículo propondremos un acercamiento a la cuestión a partir de un análisis retórico, intertextual y semiótico-estructural del libro de poemas La herida en la lengua.
\end{abstract}

Palabras clave: Otredad. Intersubjetividad. Sintaxis narrativa. Chantal Maillard. La herida en la lengua.

Abstract: Chantal Maillard's poetic creation has been built on variations from the same themes and figures, such as threads, holes, bodies, wounds, time, gazes, or difficulty to say. So, these themes and figures refer the otherness topic: how it could be represented? Are we even able to get in trully contact with others? In order to propose an approach to this topic, in this essay, the poem's book La herida en la lengua shall be analysed by using Rethorics, Intertextuality and Structural Semiotics.

Key Words: Otherness. Intersubjectivity. Narrative syntaxis. Chantal Maillard. La herida en la lengua. 


\section{INTRODUCCIÓN: “OÍDME. VENGO DE INHÓSPITOS PARAJES"}

La herida en la lengua. Inquietante umbral o paratexto para el décimo primer libro de poemas firmado por Chantal Maillard. ¿A qué alude esta herida? ¿Es el cuerpo de la hablante —en femenino - el que se encuentra herido en su misma boca, con la que habla, pero por la que también se nutre? ¿O será el sistema de la lengua, la lengua natural, también la lengua poética, la que presente una imperfección, acaso un desgarro, en su centro? La metáfora es sugerente. No menos ambigua ni plural, como corresponde a la gran Poesía.

$\mathrm{Si}$ aceptamos que sendos metaforizadores — herida y lenguadesignan mundos distintos, acercados de manera dulcemente conflictiva, las interpretaciones pueden tender al infinito. Tomando las figuras en su dimensión carnal, lo más directamente figurativa, dicha herida impediría la expresión oral, o al menos, produciría dolor o gritos. También la ingesta, pues no se puede perder de vista que el hambre es uno de los temas más aludidos en la obra de Chantal Maillard: violencia más sibilina que hiere lo mismo al cuerpo, pero, sobre todo, que confronta al sujeto con la otredad: "la vida como hambre. [...] Todo ser vivo se sostiene sobre el hambre, se sostiene sobre la violencia, y se sostiene por tanto sobre la muerte del otro", porque "todo lo que vive es un gran organismo, no podemos prescindir de ninguna de sus partes. Cuando eliminamos una parte, el resto muere. Y eso es lo que está pasando ahora" (Maillard, 2019a; 00:19:00²). La toma de conciencia traumática de toda forma de violencia - aunque sea por omisión, como le confiesa la mujer a Medea en el diálogo de La compasión dificil (2019b: s. p.) - es lo que arroja al sujeto sobre el entramado relacional del acontecer y le permite objetivizar su entorno, dentro del texto poético, sin duda, pero también fuera, en el proceso de lectura individual, encarnada.

De la otra parte, la figura de la lengua como conjunto de significantes y reglas de organización comunicativa, como semiótica-

\footnotetext{
${ }^{1}$ Cita tomada de Maillard (2015: 79).

${ }^{2}$ Para citar esta conferencia / recital emplearemos el código de tiempo de la grabación en vídeo cuyo enlace en la red se indica en el apartado de referencias final, en donde los caracteres corresponden a hora, minuto y segundo: hh:mm:ss.
} 
objeto, exige regresar sobre una de las principales cuestiones de la Teoría de la Literatura, y dentro de esta, de la Poética general. Si Wittgenstein ya nos advirtió con severidad de que los límites de mi lenguaje significan los límites de mi mundo - "Die Grenzen meiner Sprache bedeuten die Grenzen meiner Welt"3 (2009: 104)_, no menos cierto es que los poetas han librado desde antiguo una encarnizada lucha contra los mismísimos límites del lenguaje, en cuyas fronteras, en ocasiones, y en el mejor de los casos, es posible forjar improvisados funcionamientos poéticos locales —semiosis introversivas, según Jakobson, (1982: 347-395), o sistemas semi-simbólicos para la tradición post-estucturalista (víd. Greimas, 1994; Marsciani, 1988; Lancioni, 2004)—, que permiten hallar escapatorias del sentido (Greimas, 1987) a partir de imperfecciones, según la lógica lingüística, brechas, o incluso heridas en el sentido común.

La expresión poética queda planteada como una otredad a la lógica del lenguaje mismo, que permite situarse en las fronteras y observar, observarse, como quien se mira en un espejo, de modo que el otro y el mismo se duplican sobre la superficie o sintaxis reflexiva.

En las páginas siguientes se abordarán algunas claves analíticas del poemario La herida en la lengua (Maillard, 2015), centrando la atención sobre el problema de la otredad. "J'est un autre" — lo dijo Rimbaud (2008: $6)^{4}$ — cuando el yo se inscribe en el discurso; y es ese el mecanismo particular de la función poética. Desde una metodología semiológica estructural, siguiendo el modelo del recorrido generativo del sentido de A. J. Greimas (1982: 194) con base epistemológica en una Filosofía Fenomenológica (Marsciani, 1988: 6 y ss.), nos ocupamos, de un lado, del proceso de simbolización que se pone en juego en esta obra, y de la otra parte, de la eficacia comunicativa de la otredad problematizada, más que representada. Todo ello mediante el análisis en inmanencia (Greimas y Courtés, 1982: 372-373), esto es, transitando la textualidad, desentrañándola en el ejercicio analítico en tres dimensiones: 1) retórica — semántica y sintaxis de superficie—; 2) trans-textual —en conexión con otros textos de la misma autora que puedan aportar sentido, o, mejor dicho, desestabilización del sentido-, y 3) semio-narrativa — con tal de abordar, en concreto, el problema de la otredad-.

${ }^{3}$ Reproduzco el énfasis del original, según la edición consultada.

${ }^{4}$ Originalmente, "Lettre à Georges Izambard", 13 de mayo de 1871. 


\section{2. "LENGUAJE: LUJOSA ENCUADERNACIÓN / DE LA IGNORANCIA" ": EN TORNO A LA LENGUA POÉTICA}

Sobre el papel crucial de la Poesía como forma desestabilizadora de la semiosis y del sentido, no hay que olvidar que Chantal Maillard, además de brillante escritora, ha sido profesora titular de Filosofía Estética y Teoría de las Artes en la Universidad de Málaga hasta el año 2000, faceta en la que sus investigaciones sobre la Razón poética de María Zambrano (Maillard, 1992, 1998 y 1999; cf. Zambrano, 1986, 2001 y 2002) son de máxima relevancia: "[...] llegar a una conciliación entre el conocimiento racional y el sentir poético reparando de ese modo en el desgarro entre el mundo universal de las ideas y el ámbito de lo particular que el arte representa" (Fernández Castillo, 2009). Razón poética que, con el tiempo, devino Razón estética:

La razón estética le devuelve a la razón los componentes sustraídos por la ontología platonizante. Más pretenciosa que la razón ilustrada o científica por cuanto queda menos limitada, pretenderá aprehender no los hechos ni las cosas o los seres en su engañosa y útil determinación, sino el huidizo proceso de estar-siendo de lo fenoménico, su perpetuo constituirse para I con la conciencia implicándose en la fuerza constituyente del universo (Maillard, 1999: 133).

No existe trasvase o traducción entre Filosofía y Poesía, antes bien, son la misma cosa en su acontecer en la palabra, $\lambda o ́ \gamma o \varsigma$, que significa habla, discurso o razonamiento, y cuya raíz etimológica del indoeuropeo le $\bar{g}$ designa recoger, seleccionar, elegir. Recolectar y dar forma a los mismos materiales a través de la sustancia o molde de los géneros de escritura: "Yo suelo llamar a estos libros híbridos" — comenta la autora— "porque no son ni un ensayo, ni un libro de poemas, ni una obra teatral, son una mezcla un poco de todo ello" (Maillard, 2019a; 00:15:25). Palabra que acontece en la forma manifestada - o en las formas alternativas, paralelas - y que, por ello, puede proporcionar una confrontación entre el sujeto y su

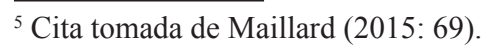


entorno, también con el sentido en tanto que relación del yo con lo que acontece. Matar a Platón (2004), como lema y proyecto estético, solo es posible a través del trabajo con el lenguaje, en el lenguaje. Urge renovar la expresión poética, generar nuevos marcos y sistemas de significación por un imperativo ético, en un mundo que prefiere mirar hacia otro lado ante el hambre, la violencia estructural, la muerte. Aunque ello arroje al lenguaje hacia el malditismo. En torno a La compasión dificil, que trata precisamente de la dificultad de tomar conciencia del otro - acaso de su imposibilidad radical—, sin imposturas, sin hipocresía, reflexiona la autora al respecto:

[...] digo cosas que no están bien vistas, no son políticamente correctas y molestan. Molestan. Bueno, precisamente porque molestan hay que decirlas. Yo me siento en el deber, por la honestidad de quien escribe, de decir lo que pienso. [...] [El suicidio, el respeto a las creencias, el hambre, la vida no es un bien, el nacimiento...] Cuando hablamos de Literatura, cuando hablamos de Poesía, todavía hay quien espera cosas melosas, bonitas, lacitos de colores que le ponemos a las palabras... palabras como lacitos, como caramelos... ¡Ay, qué bonito! Lo siento, no soy así. [...] ¿ Y aún seguiréis confundiendo el poema con la sensiblería? ¿A qué llamáis amor? ¿A qué belleza? ${ }^{6}$ (Maillard, 2019a; 00:17:40, 00:20:10 y 00:40:45).

La metáfora es, en primer lugar, la principal figura de otredad expresiva que permite la renovación del lenguaje. Al funcionamiento poético del lenguaje como generador de realidades simbólicas re-creadas, alude Maillard comentando el pensamiento de Zambrano:

El sujeto no sólo emplea ${ }^{7}$ la metáfora, sino que la efectúa, la actúa. La metáfora es ante todo un acto [...], un acto que crea nueva realidad en el lenguaje. Es decir, que tiene un estatus epistemológico absolutamente central: me atrevo a decir [que en] toda teoría del pensamiento y toda epistemología [...] el primer foco de atención, por ser el núcleo de ese poder de recreación, debería ser la actividad metafórica (Maillard, 1992: 107 y 115).

\footnotetext{
${ }^{6}$ Este último fragmento, que me ha parecido ilustrativo incorporar al final de esta cita, lo recita la autora leyendo el diálogo teatral entre la mujer y Medea de La compasión difícil (2019b: s. p.).

${ }^{7} \mathrm{El}$ énfasis procede del original.
} 
En segundo lugar, desde sus Diarios Indios hasta sus poemas y ensayos (cf. Aguirre de Cárcer Girón, 2015: 194 y ss.), la autora también busca a través de la expresión del yo lírico un punto de observación externo, alterno; lo que ha convenido en denominar como la técnica del observador: "aquel que me mira siendo - en el acontecer, no ya en el ser-; aquel que me mira a mí - y me convierte en objeto de contemplación: el otro-, pero que no es el mí o el personaje interno que experimenta al tiempo que emite juicios" (Aguirre de Cárcer Girón, 2016: s. p.). El observador o contemplador consiste en una figura ajena que me mira desde lejos y que me expresa a mí, a mis visiones, impresiones o sentimientos, desde una perspectiva extrañada, dotándome de existencia discursiva trascendente. El otro deviene el mismo por imperativo ético y estético:

\begin{abstract}
Más allá del observador: el camino. El observador no es la otra orilla, la otra orilla está más allá del observador y de lo observado. El observador no es sino la misma orilla, aunque desdoblada.

El observador es aquel que me mira siendo, deseando, ocupada en la tarea de ser. El observador puede sonreir mientras lloro al intentar vanamente alcanzar lo que quiero y no baja la guardia cuando lo consigo. Me observa en la tristeza y también, a veces, en el gozo. El observador está al otro lado, pero también del lado en el que estoy. Su distancia pertenece al mundo de las diferencias. Él no juzga, pero su observar le distingue. No se identifica con los seres o las cosas que desea, ni con ninguno de mis estados de ánimo, pero él es parte del juego de la conciencia. [...] (Maillard, 2005: 74).
\end{abstract}

El carácter nómada de la vida y la obra de Chantal Maillard así nos lo confirma: sus orígenes belgas, su juventud en Málaga, la experiencia cuestionadora de una cultura tan distinta como es la de la India, también la experiencia del dolor a través de la confrontación con la enfermedad y la muerte, han exigido a la autora la búsqueda de una otredad, de un noyo, no-aquí y no-ahora - un triple débrayage enunciativo de desemplazamiento, diríamos desde la Teoría de la Enunciación (Greimas y Courtés, 1982: 113 y 138)—, que permita negociar con estas figuras temáticas en el seno de la escritura, en el interior de la forma poética - en un sentido amplio, no solo en las escrituras líricas-, con tal de generar un espacio habitable y compartido con los potenciales receptores, no replegado, no egoísta, no críptico, sino abierto a las lectoras y lectores. De ahí, quizás, la dureza de algunas de sus creaciones, especialmente en La compasión 
difícil (2019b), dentro de la sección teatral dialogada "Conversaciones con Medea”, o el próximamente por venir Medea (en prensa), versión lírica sobre el mismo tema en el que la heroína trágica es el otro: la extranjera de la Cólquide en el patriarcado aqueo.

\section{3. "QUÉ EXTRAÑO ES TODO ESTO / REALMENTE, QUÉ EXTRAÑO". FIGURAS DE LA OTREDAD}

\subsection{Cuerpos y miradas: "Y la mano investiga el / lacrimal o el surco la memoria" $"$}

También en su obra ensayística y periodística, Chantal Maillard se ha preocupado por el problema de la otredad desde una perspectiva que afecta no ya a la escritura poética en exclusiva, sino en un sentido amplio, a una dimensión que, desde la Semiología Estructural, bien podríamos plantear desde un prisma Socio-Semiótico, pues alude a toda forma simbólica de relación. El diario El País publicaba el 27 de noviembre de 2018 el artículo "El semejante", en el que Maillard afirmaba lo siguiente en el contexto de la crispación política de aquellos días:

$Y$ es que, lo que de hecho ${ }^{10}$ ocurre, es que lo que nos importa es tan solo lo que nos concierne. Y lo que hoy en día nos pone a salvo de que todo lo que ocurre en el mundo nos concierna es que lo recibimos por los mismos medios y en el mismo recuadro en el que recibimos la ficción. Nos pone a salvo el hecho de que las emociones generadas por lo que vemos en la pantalla sean las propias del espectáculo, emociones transformadas por la representación y, por tanto, neutralizadas en cuanto germen de rebeldía. Porque si recibiésemos lo representado no en directo ${ }^{11}$, sino directamente, es decir, en presencia viva, el impacto sería de tal magnitud -o al menos eso quiero pensar - que no nos dejaría indiferentes en nuestra diferencia. De repente nos sentiríamos concernidos. De repente el otro, los otros, todo lo otro habría saltado la valla (Maillard, 2018b: s. p.).

\footnotetext{
${ }^{8}$ Cita tomada de Maillard (2015: 55).

${ }^{9}$ Cita tomada de Maillard (2015: 119).

${ }^{10} \mathrm{El}$ énfasis procede del original.

${ }^{11}$ El énfasis procede del original.
} 
Para simbolizarnos, para representarnos como identidad — esto es, idénticos, análogos a otros; y distintos de lo diverso que salta desde el otro lado de la valla de la forma visual o poética, interpelándonos directamente-, algo o alguien tiene que mirarnos desde fuera. Incluso si es una figura sin forma todavía sensible ${ }^{12}$. Acaso como el personaje Cual del poema-película del mismo nombre, o de sus posteriores revisiones (2007, 2009 b y 2018a); o la presencia intermitente del gato que me observa en silencio, constituyéndome de un modo incluso insoportable, como objeto de su mirada en un lenguaje silencioso y desconocido que no alcanzo a comprender.

Pero es que el otro - ni siquiera el yo-, no se deja aprehender con facilidad cuando soy capaz de trascender en la escritura especular el egoísmo del mí: "[...] es difícil compadecer al ser humano" (Maillard, 2019a; 00:20:45). Y para ello, se emplea "el cuerpo como lanzadera" (Maillard, 2015: 123). El cuerpo del yo lírico en el discurso poético, pero también el cuerpo del lenguaje mismo. El lenguaje poético tiene la responsabilidad, en definitiva, de provocar ese impacto desestabilizador que ya no tienen otras formas de comunicación, porque las percibimos como simulacros.

\subsection{Sintaxis narrativa e intersubjetividad desde la Semiótica estructural}

Ciertamente, la Fenomenología filosófica de Edmund Husserl ya había previsto en la quinta de sus Meditaciones cartesianas que la esfera de la intencionalidad jamás llega a una plena correspondencia entre la idea del yo soy y de el mundo es, sino que surge como momento de sentido ante una alteridad a un tiempo constituyente y constituida (Marsciani, 1988: 6 y ss.). Tal es también el fundamento de la racionalidad semiótica estructural, en tanto que A. J. Greimas establece la sintaxis fundamental del sentido sobre el eje de una interdependencia narrativa sujeto-objeto - o sujetosujeto, en la sintaxis intersubjetiva - en función de un valor en circulación que los hace emerger a ambos como actores con existencia semiótica

\footnotetext{
${ }^{12}$ Aludo aquí al concepto de Figura de Louis Hjelmslev como elemento anterior a su aprehensión como forma del contenido o de la expresión por mediación de una sustancia (1980: 71; cf. Greimas y Courtés, 1982, I: 175).
} 
(1973: 186-188; 1987: 28-30; 1989: 22-31). Es en la estructura semionarrativa, en esta negociación en torno a un valor atribuido, en donde hay sentido.

Entenderemos por tanto dicha reciprocidad como una construcción que recorta al fenómeno con respecto del mundo, no como un dato en bruto que le pertenece. Es más: ello proyecta ese mundo como universo simbólico provisto de un sentido, en donde se incardinan el objeto y la subjetividad, definidas como instancias movilizadas por una incitación que las convoca. Incluso lo que se podría denominar bajo el concepto de mundo natural, por ende, se presenta como un paisaje conformado por el universo de sentido en el que emerge el fenómeno, más allá de su datidad física (Greimas, 1989: 119 y ss.).

\section{4. "IMPERFECTO SISTEMA DE RESONANCIA" CICIOS ANALÍTICOS}

\subsection{La herida en la lengua}

¿Cómo se produce en el objeto de estudio este proceso paralelo de deconstrucción / fuga del lenguaje — vertiente semántica—, y constitución del yo / mí desde un punto de subjetivación / objetivación externo vertiente sintáctica-?

En la primera sección de La herida en la lengua - que lleva el mismo título - pasamos desde las "Adherencias" hasta el "Desgarro". El dolor producido por aquello que no se puede o no se sabe decir, supone un punto ciego en el lenguaje, y, por tanto, un reto del cual, el proceso de simbolización debe hacerse cargo con urgencia. El punto de subjetivación que emplea Maillard en la manifestación del yo lírico de esta parte se debate entre la sensualidad del "Polvo de avispas"14 y el fruto de "La cereza", el desconcierto del "Desprendimiento", "La Aguja / Merodeos" o el "Morderse la lengua". Finalmente, asistimos al extremo del grito espontáneo en la sección titulada "El desgarro". El problema del yo, del otro y del mundo mediador entre ambos - el fenómeno que acontece-

\footnotetext{
${ }^{13}$ Cita tomada de Maillard (2015: 141).

${ }^{14}$ Cuyo título es el del cuadernillo de 2011 en Árbol de Poe, lo que nos habla una vez más del acontecer, del devenir de las escrituras de la autora.
} 
termina por ser algo innombrable, inasible, dentro de los límites formales del lenguaje, $\lambda o ́ \gamma o \varsigma$ o forma simbólica. Por eso son frecuentes los espacios en blanco, los interrogantes y los silencios, cuando no existe palabra alguna que pueda ocupar el lugar señalado en el poema:

\author{
Subvertir dice \\ el territorio del logos. Un \\ nuevo aprendizaje \\ del mundo - ¿mundo? - de \\ la realidad $-i ?-$ de \\ la conciencia $-i ?-d e$ \\ eso-i?
}

Basta. Dejémoslo asi

por ahora (Maillard, 2015: 71).

El desgarro en el cuerpo del yo, también en el cuerpo del lenguaje, se manifiesta con especial intensidad en el siguiente poema, sea desde la forma de la expresión, sea bajo la forma del contenido:

Hasta que de repente un eco
distorsiona
sacude y atraviesa
el paisaje
lo
traspasa
e impulsa
adentro de la córnea
la extraña coincidencia
de lo desemejante.
Entonces algo
en este ser de hueso
cartílagos endebles
y bajo entendimiento
torpemente advierte
en sí
la herida que es de otro
y le arde (Maillard, 2015: 101).

El poema se rompe literalmente —a juzgar por la distribución 
tipográfica - en dos estrofas desiguales, de 10 y 8 versos anisosilábicos. En la primera estrofa, de hecho, el anisosilabismo juega de manera simétrica, dibujando en negativo — pues el blanco de la página genera la forma que deja libre el negro de la tinta impresa - un triángulo vertical, con su centro en el verso 5: el pronombre neutro lo. De esta manera, el poema pierde ritmo hacia su mitad, aprovechando los encabalgamientos de los versos 2-3 y 6-7-8. El motor de decrecimiento se encuentra en la bimembración "sacude y atraviesa" —en el mismo verso-, mientras que el de aceleración aparece con la bimebración "traspasa / e impulsa — esta vez encabalgada-, con el sonido $a$ como conductor entre versos sucesivos — "traspasa", "impulsa", "acelera"-, generando continuidad. Movimiento de salida hacia fuera y entrada hacia adentro, hacia la "córnea" en el verso 8 , después de que las figuras transitivas verbales de la violencia ejercida por el fantasma sin cuerpo del eco - todo eco ha perdido su origensusciten la conciencia de lo desemejante.

En la segunda estrofa el ritmo cambia. El sonido aliterativo de la $s$ líquida va conduciendo el fluir sonoro - "Entonces $[\ldots]$ / en este ser de hueso / cartílagos endebles"-, sinuoso, líquido, que expresa tan bien la debilidad del cuerpo y del entendimiento - $\lambda o ́ \gamma o \varsigma$ - ante el lenguaje disuelto y reformulado, ante el cuerpo lacerado, abandonado y duplicado en la otredad. Arde la herida avistada en el otro que este movimiento ha producido en la conciencia / percepción del yo de este poema, como si estuviera en el cuerpo propio: se ha alcanzado la compasión. Además, el verbo conjugado, "arde", queda aislado en el verso octavo de la segunda estrofa, separado del resto con la conjunción copulativa y que añade, suma, suscita un aparte, en donde la lectura se queda detenida, como en una estancia, dejando en suspenso el discurso, pero activa la imaginación del lector, pues de imágenes se habla en todo momento.

Acontece así la otredad, en esa última imagen sostenida: la imagen del otro que soy yo, que me une y me vincula hasta el punto de que - en una potente figura de la poética material con el elemento fuego- arde la herida en mi carne por identificación con el cuerpo del poema.

\subsection{Sidermitas}

En la segunda parte, "Sidermitas", la escritura se vuelve densa y 
opaca, a través de versos fragmentarios. Los sidermitas son una raza de humanos heridos por el desgarro infringido por otros humanos sin nombre y casi sin cuerpo en el poema, pero también por la imposibilidad de decir, y por tanto, de definirse como sujetos objetivadores de un mundo racional a su alrededor. Dermis como piel, pero también como túnel-boca por el que la forma - lingüística - se cae. La nueva metáfora en este punto es la del agujero, a través del cual el contemplador y el sujeto —el mi — caen abrazados, profundizando en la realidad y sus circunstancias:

\begin{abstract}
Cuídate, sidermita, de la estirpe del hombre. Desprovistos de instinto transforman en creencia lo que la lengua dicta. De entre sus dos origenes uno lo han perdido, el otro les confunde.
\end{abstract}

Cuidate, sidermita, de la estirpe del Hombre. No controlan

la medida del fuego (Maillard, 2015: 131).

La caída en el agujero supone una apertura a lo universal, una preocupación por lo colectivo, lo común redescubierto como forma única que emerge y envuelve tanto el escenario textual como a los cuerpos $-\mathrm{O}$ figuras sin cuerpo articulado, más bien- que lo habitan. Un lenguaje renovado por la metáfora desea expresarlo, y lo hace a través de un hablar profético en donde abundan los imperativos - cuídate - o las apelaciones a un enunciatario proyectado a través de la fingida prédica invocadora de un tú.

\title{
4.3. Balbuceos
}

La tercera sección, "Balbuceos"15, combina el poema en prosa con los versos libres en estrofas anisométricas, en la doble confrontación del yo que se busca - al tiempo que recrea el lenguaje poético-, con las figuras del otro, que observa desde lejos. El yo -o los yoes, por cierto, enunciados

\footnotetext{
${ }^{15}$ Cuyo título es el del cuadernillo de 2009 en Árbol de Poe, lo que nos habla una vez más del acontecer, del devenir de las escrituras de la autora (2009a).
} 
en femenino, como alternativa, a mi juicio, al masculino genérico tan injustamente uniformante durante demasiados siglos- emergen como figuras objetivadas en el momento en que se saben observadas, miradas, interpeladas por la otredad:

[...] Intrusa de mi mundo y del ajeno, no hallo lugar para el descanso.

La fe de los comienzos, no.

El perdón

no.

Sólo

el balbuceo.

La salvación

no.

Sólo

el balbuceo.

Después del grito

el balbuceo.

Asolada

el balbuceo.

Mis pasos doblándose hacia dentro.

La mente desposeída de estrategias.

Sólo

el balbuceo.

Dolor, ni tan siquiera - palabra sin sentido- No abro las cortinas. Ninguna cortina. La habitación a oscuras. Málaga, Damasco, Delhi, en todas las ciudades la vida me es ajena. Todas las ventanas son la misma ventana. Todas las aceras reciben el mismo cuerpo. La misma soledad cayendo, excesiva. Morir es un exceso. Me ex-

cedo. Balbuceo [...] (Maillard, 2015: 162-163).

La escritura se deshilvana en este fragmento final del libro. Llega a ser una escritura plenamenta híbrida: el verso se deshace, o se compacta 
en fragmentos seguidos en prosa, enunciados entre la confesionalidad del diario íntimo - experiencias como la soledad, lugares vividos tales que Málaga, Damasco o Delhi, imágenes evocadas de aceras y ventanas...y el ensayo que reflexiona sobre los límites de la conciencia dialógica — dia o duplicada; logos o palabra —. Y finalmente, el discurso se rompe: la acumulación desmesurada del exceso se quiebra, hasta el punto de que la palabra se divide y el sentido cae arrojado en la derrota, en el ceder. Ceder ante la otredad del mí que me trasciende y constituye como sujeto - o inter-sujeto en una relación sintáctica intersubjetiva, no ya objetiva nunca más - Ceder ante la otredad del lenguaje que hay que herir $-\mathrm{y}$ morir- en su centro si todavía se quiere aspirar a decir algo.

\section{CONCLUSIONES: OTREDAD, POÉTICA, INTERSUBJETIVIDAD}

Bien es sabido que la enunciación en el discurso poético podría generar una serie de mundos no ya representados, sino suscitados, dando lugar a un tipo concreto de semiosis, en la que las categorías semánticas se pactan categoría a categoría, como en la Función Poética o como nos descubren los sistemas semi-simbólicos, annico mabroullon@ucm.esn a travvértaciue la forma aparezca manifestada comentando el pensamiento de Zambranboor la alteridadd a sálogos al modelo jakobsoniano y fundamento del proceso general de simbolización, sea cual fuera la sustancia en la que la forma aparezca manifestada. En la vertiente sintáctica, por otra parte, ello daría lugar a una alteridad: aquella que no se limita al reconocimiento verosímil, antes bien, genera una otredad habitable en la que, cuanto menos, cuestionar el sentido común que sostiene nuestra manifestación o expresión simbólica como sujetos enunciados, proyectados, desde una figura externa y lejana que señala o constituye nuestra propia existencia en el espacio simbólico, dentro y fuera del poema. Saltar la valla, como sugiere la autora, me afecta e interpela como lector - en un circuito externo al enunciativo, pero superpuesto a la figura del enunciatario- desde una moral de la otredad, sin la cual, nada puede cobrar existencia semiótica o simbólica, que es nuestra única forma de existencia consciente y, por ello, plenamente humanizada. 


\section{REFERENCIAS BIBLIOGRÁFICAS}

AGUIRRE DE CÁRCER GIRÓN, N. (2015). “Málaga-Benarés-Bélgica. El recorrido de la obra de Chantal Maillard". Tropelías 23, 184205. Disponible en línea: https://doi.org/10.26754/ojs_tropelias/ tropelias.201523743 [19/03/2020].

(2016). "Nuevas fronteras en la referencialidad del yo: los diarios de Chantal Maillard". JACLR: Journal of Artistic Creation and Literary Research 4.2, 1-9.

FERNÁNDEZ CASTILLO, J. L. (2009). "Filosofía y poesía en Matar a Platón de Chantal Maillard”. Espéculo. Revista de Estudios Literarios 42, s. p. Disponible en línea: http://webs.ucm.es/info/especulo/ numero42/maplaton.html [19/03/2020].

GREIMAS, A. J. (1973). En torno al sentido. Ensayos semióticos. Madrid: Fragua.

(1987). De l'imperfection. Périgueux: P. Fanlac.

(1989). Del sentido II. Ensayos semióticos. Madrid: Gredos.

(1994). "Semiótica figurativa y semiótica plástica". En Figuras y estrategias. En torno a una semiótica de la visual, G. Hernández Aguilar (ed.), 17-42. Madrid: Siglo XXI.

GREIMAS, A. J. y COURTÉS, J. (1982). Diccionario razonado de la teoría del lenguaje. 2 vols. Madrid: Gredos.

JAKOBSON, R. (1982). Ensayos de lingüistica general. Barcelona: Seix Barral.

LANCIONI, T. (2004). "Tagliole e collari - Il semi-simbolico e lo studio della dimensione figurativa dei testi”. Carte Semiotiche 6-7, 22-42.

MAILLARD, C. (1992). La creación por la metáfora. Introducción a la razón-poética. Barcelona: Anthropos.

(1998). La razón estética. Barcelona: Galaxia Gutemberg. (1999). "La razón estética: una propuesta para el próximo milenio". Contrastes. Revista Interdisciplinar de Filosofía 4, 121-133. (2004). Matar a Platón. Escribir. Barcelona: Tusquets. (2005). Diarios indios. Valencia: Pre-Textos. (2007). Hilos. Cual. Barcelona: Tusquets. (2009a). Balbuceos. Málaga: Árbol de Poe. 
(2009b). Cual. Málaga: Diputación de Málaga / Centro Cultural Generación del 27.

(2011). Polvo de avispas. Málaga: Árbol de Poe.

(2015). La herida en la lengua. Barcelona: Tusquets.

(2018a). Cual menguando. Barcelona: Tusquets.

(2018b). "El Semejante". El País, 27 de noviembre. Disponible en línea: https://elpais.com/elpais/2018/11/26/opinion/1543253697_888911.html [19/03/2020].

(2019a). "Conversaciones con Medea". Conferencia pronunciada en el Aula de Poesía Ateneo / Universidad de Sevilla, 25 de octubre. Disponible en línea: https://youtu.be/7sbk7gqCfOE [23/11/2019]. (2019b). La compasión dificil. Barcelona: Galaxia Gutemberg. (en prensa). Medea.

MARSCIANI, F. (1988). Ricerche intorno alla razionalità semiotica. Bologna: Università di Bologna.

RIMBAUD, A. (2008). Lettres dites "du voyant”. Edición facsimilar con transcripción, disponible en línea: $h t t p: / / w w w$.artyuiop.fr/artyuiop/ Arthur_Rimbaud_-_les_lettres_du_voyant_files/artyuiop $10 \mathrm{~A}$ Rimbaud-Les\%20lettres\%20du\%20voyant.pdf [23/11/2019].

WITTGENSTEIN, L. (2009). Tractatus logico-philosophicus. Investigaciones filosóficas sobre la certeza, ed. bilingüe. Madrid: Gredos.

ZAMBRANO, M. (1986). El sueño creador. Madrid: Turner. (2001). Filosofía y poesía. México: Fondo de Cultura Económica. (2002). Claros del bosque. Barcelona: Seix Barral.

Recibido el 2 de marzo de 2020.

Aceptado el 15 de abril de 2020. 